\title{
The uncertainty analysis of the MODIS GPP product in global maize croplands
}

Article

Accepted Version

Huang, X., Ma, M., Wang, X., Tang, X. and Yang, H. (2018)

The uncertainty analysis of the MODIS GPP product in global maize croplands. Frontiers of Earth Science, 12 (4). pp. 739749. ISSN 2095-0195 doi: https://doi.org/10.1007/s11707-0180716-x Available at https://centaur.reading.ac.uk/80036/

It is advisable to refer to the publisher's version if you intend to cite from the work. See Guidance on citing.

To link to this article DOI: http://dx.doi.org/10.1007/s11707-018-0716-x

Publisher: Springer

All outputs in CentAUR are protected by Intellectual Property Rights law, including copyright law. Copyright and IPR is retained by the creators or other copyright holders. Terms and conditions for use of this material are defined in the End User Agreement.

\section{www.reading.ac.uk/centaur}

\section{CentAUR}

Central Archive at the University of Reading

Reading's research outputs online 


\section{The uncertainty analysis of the MODIS GPP product in}

\section{global maize croplands}

Xiaojuan Huang ${ }^{1,2}$, Mingguo Ma ${ }^{1,2} *$, Xufeng Wang ${ }^{3}$ Xuguang Tang ${ }^{1,2}$, and Hong Yang $^{4}$

${ }^{1}$ Chongqing Engineering Research Center for Remote Sensing Big Data Application, Southwest University, Chongqing, China;

${ }^{2}$ Chongqing Key Laboratory of Karst Environment, School of Geographical Sciences, Southwest University, Chongqing, China;

${ }^{3}$ Northwest Institute of Eco-environment and Resources, Chinese Academy of Science, Lanzhou, China;

${ }^{4}$ Department of Geography and Environmental Science, University of Reading, Reading, RG6 6AB, UK

* Correspondence:

Dr Mingguo Ma

$\underline{\text { mmg@swu.edu.cn }}$

Keywords: MODIS GPP; eddy covariance; maize cropland; validation; improvement

\section{Abstract}

Gross primary productivity (GPP) is very important in the global carbon cycle. Currently, the newly released estimates of 8-day GPP at 500-m spatial resolution (Collection 6) are provided by the Moderate Resolution Imaging Spectroradiometer (MODIS) Land Science Team for the global land surface via the improved light use efficiency (LUE) model. However, few studies have evaluated its performance. In this study, the MODIS GPP products (GPPMOD) were compared with the observed GPP $\left(\mathrm{GPP}_{\mathrm{EC}}\right)$ values from site-level eddy covariance measurements over seven maize flux sites in different areas around the world. The results indicate that the annual GPPMOD was underestimated by $6 \%-58 \%$ across sites. Nevertheless, after incorporating the parameters of the calibrated LUE, the measurements of meteorological variables and the reconstructed Fractional Photosynthetic Active Radiation (FPAR) into the GPP $\mathrm{POD}_{\mathrm{M}}$ algorithm in steps, the accuracies of GPP ${ }_{M O D}$ estimates were improved greatly, albeit to varying degrees. The differences between the GPPMOD and the GPPEC were primarily due to the magnitude of LUE and FPAR. The underestimate of maize cropland LUE was a widespread problem which exerted the largest impact on the GPPMOD algorithm. In American and European sites, the performance of the FPAR exhibited distinct differences in capturing vegetation GPP in growing season due to the canopy heterogeneity. In addition, at the DE-Kli site, the GPPMOD abruptly appeared extreme low values during the growing season because of the contaminated FPAR from a continuous rainy season, which was relevant with the local weather. After correcting 
the noise of the FPAR, the accuracy of the GPP $\mathrm{MOD}_{\text {was }}$ improved by approximately $14 \%$. Therefore, it is crucial to further improve the accuracy of global GPPMOD, especially for the maize crop ecosystem, to maintain food security and better understand global carbon cycle.

\section{Introduction}

Gross primary productivity (GPP) is important for the global carbon cycle between the biosphere and other systems (Lai et al., 2016). It is still a big challenge to accurately quantify the global terrestrial GPP at high spatial and temporal resolutions (Zhang et al., 2015). At the ecosystem level, the eddy covariance technique has been widely used to measure the exchanges of the $\mathrm{CO}_{2}$, water, and energy between the atmosphere and the land surface (Jung et al., 2011). The light use efficiency (LUE), first proposed by Monteith (Monteith, 1972), is one of approaches to estimate GPP. With the development of geographic information system (GIS) technology, it is increasingly easy to use remote sensing (RS) technology to observe the earth and provide continuous data for the LUE model.

Since 2000, the Moderate Resolution Imaging Spectroradiometer has provided a new way to monitor GPP regularly from space with a spatial resolution of $500 \mathrm{~m}$ and the temporal resolution of 8 days (Running et al., 2004), and provided datasets from Collection 4 (C4) to Collection 6 (C6). Compared with C6, there are two main problems with the $\mathrm{C} 4 \mathrm{MOD} 17 \mathrm{~A} 2 \mathrm{H}$ dataset. Firstly, in some regions with higher frequencies of cloud cover, the 8-day Maximum Value Composite (MVC) is still contaminated by clouds, yielding incorrect 8-day GPP values. Secondly, the C4 MOD17A2H dataset fails to account in the algorithm for the mismatched spatial resolution between a 1-km Moderate Resolution Imaging Spectroradiometer (MODIS) pixel and the corresponding $1^{\circ} \times 1.25^{\circ}$ meteorological data from the Data Assimilation Office (DAO). The C4 MOD17A2H data were then improved for Collection 5 (C5) based on the development of the MODIS fraction absorbed photosynthetically active radiation (FPAR) and plant maintenance respiration by National Aeronautics and Space Administration (NASA) in 2007 (Zhao et al., 2011). At present, the C6 of MOD17A2 GPP products have higher quality than the previous collections with a spatial resolution from $500 \mathrm{~m}$ to $1 \mathrm{~km}$ and improvement in the maximum LUE of the crop and other parameters in the algorithm.

It is necessary to validate the C6 MODIS GPP (GPPMOD) products with local observation (Fu et al., 2012). It is a challenging task to analyze the uncertainly of

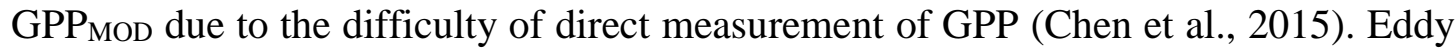
covariance (EC) flux towers have been increasingly used to measure GPP indirectly by partitioning the net ecosystem exchange (NEE) into the ecosystem respiration (ER) during the daylight periods. A growing number of flux sites have been used to validate the MODIS product (Turner, 2003; He et al., 2010; Fu et al., 2012; Wang et al., 2013; Tang et al., 2015). Additionally, the eddy covariance technique has made the calibration process of the LUE more feasible than ever before. 
$\mathrm{GPP}_{\mathrm{MOD}}$ has been validated in forest (Gebremichael and Barros, 2006; He et al., 2010), grassland, and cropland (Zhang et al., 2008; Fu et al., 2012; Wang et al., 2013) with different biomes across different climate zones, indicating that GPPMOD products were overestimated at low productivity sites because of the overestimate of FPAR and underestimated at higher productivity sites due to the underestimate of LUE (Fu et al., 2012). In other words, there is a large underestimate of the GPPMOD due to the uncertainty of the maximum LUE and FPAR in some areas. In the GPPMOD algorithm, the parameter of LUE, which depends on the simple look-up table approach, is the most uncertain component (Running et al., 1999; Wang et al., 2013). In addition, the MODIS FPAR is subject to uncertainty because of atmospheric conditions during the satellite overpass, view angle geometry, and canopy heterogeneity (Cohen et al., 2003; Fensholt et al., 2004).

Crops account for approximately 24\% of the earth's land surface (Peng and Gitelson, 2011). Maize is one of the primary foods for human and one of the essential fodder for animals. Therefore, it is very important to accurately estimate the maize GPP (Gitelson, 2008). However, few works have validated the maize GPP. Wang et al. (2013) validated the GPPMOD product at 4 maize sites in northern China and found that the LUE was the primary reason for the underestimate of the GPP.

This study focuses on the validation of the GPP $\mathrm{MOD}_{\mathrm{D}}$ performance on global maize cropland and aim to make marked improvement of the accuracy. To acquire the estimate of GPPMOD, this study relied on the GPPмод algorithm driven by the local meteorological data and the LUE calibrated by the seven eddy covariance flux towers and reconstructed FPAR. The objectives are 1) to assess the performance of the MODIS GPP products in maize crops at seven sites around the world; and 2) to identify the parameters influencing the regional GPPмоD.

\section{Data and Methods}

\subsection{Flux sites}

The FLUXNET2015 Dataset provide the GPP product using eddy covariance flux tower measurement. In this study, GPP of seven maize sites from the FLUXNET2015 Dataset around the world were selected (Table 1, Figure 1). More detailed descriptions of these sites can be obtained by the websites for Fluxdata (http://fluxnet.fluxdata.org) and ChinaFLUX (http://chinaflux.org/index.aspx).

American sites including US-Ne1, US-Ne2 and US-Ne3 are large production fields. US-Ne1 and US-Ne2 sites are equipped with center pivot system for irrigation while the US-Ne3 site relies on rainfall. The irrigated sites (US-Ne1 and US-Ne2) have a long history of more than 10-years of maize-soybean rotation and no-till practice. The rainfed site (US-Ne3) has a variable cultivation history with wheat, soybean, oat and maize.

European site of DE-Kli is located $4 \mathrm{~km}$ south of the Tharandt Forest in Germany. This site has functioned solely as cropland since 1975. The eddy covariance measurements started in May 2004. The crop rotation was followed by rapeseed (2004/2005), winter wheat (2005/2006), maize (2007), and spring barley (2008). European site of FR-Gri lies in a large cropland field in a plateau situation close to a 
farm with cattle. The crop rotation here was followed by maize (2005), winter wheat (2005/2006), and barley (2007).

Asian site of CN_DM is located in typical irrigated farmland in Daman village, Gansu Province, Northwest China, with a primary crop of maize (Tang et al., 2017). The precipitation in this site is about $100-250 \mathrm{~mm}$ every year with continental arid climate: dry and hot in summer and cold in winter. Asian site of CN_YC lies in Yucheng County, Shangdong Province, North China, with a crop rotation of wheat and maize over one year. The annual mean temperature is about $13^{\circ} \mathrm{C}$ and the annual precipitation is approximately $528 \mathrm{~mm}$.

TABLE 1. Characteristics of the study sites.

\begin{tabular}{|c|c|c|c|c|c|c|}
\hline Site & Site name & Country & Latitude & Longitude & Data period & Reference \\
\hline \multirow{3}{*}{ US_Ne1 } & Mead - irrigated & & & 96.4766 & & \multirow{4}{*}{ (Verma et al., 2005) } \\
\hline & continuous maize site & USA & 41.1651 & $\mathrm{~W}$ & 2001-2011 & \\
\hline & Mead - irrigated & & & & & \\
\hline \multirow[t]{2}{*}{ US_Ne2 } & maize-soybean & \multicolumn{4}{|c|}{96.4701} & \\
\hline & rotation site & USA & 41.1649 & W & 2001-2011 & (Verma et al., 2005) \\
\hline \multirow{3}{*}{ US_Ne3 } & Mead - rainfed maize- & & & 96.4397 & & \multirow{2}{*}{ (Verma et al., 2005) } \\
\hline & soybean rotation site & USA & 41.1797 & W & 2001-2011 & \\
\hline & & & & & & (Gilmanov et al., \\
\hline DE_Kli & Klingenberg & Germany & 50.8929 & $13.5225 \mathrm{E}$ & 2007 & 2010) \\
\hline \multirow[t]{2}{*}{ FR_Gri } & Grignon & France & 48.8442 & $1.9519 \mathrm{E}$ & 2005 & (Lehuger et al., 2010) \\
\hline & & & & 116.5667 & & \\
\hline \multirow[t]{2}{*}{ CN_YC } & Yucheng & China & 36.8333 & $\mathrm{E}$ & $2012-2013$ & (Xiao et al., 2009) \\
\hline & & & & 100.3722 & & \\
\hline CN_DM & Daman & China & 38.8556 & $\mathrm{E}$ & 2013-2014 & (Wang et al., 2013) \\
\hline
\end{tabular}




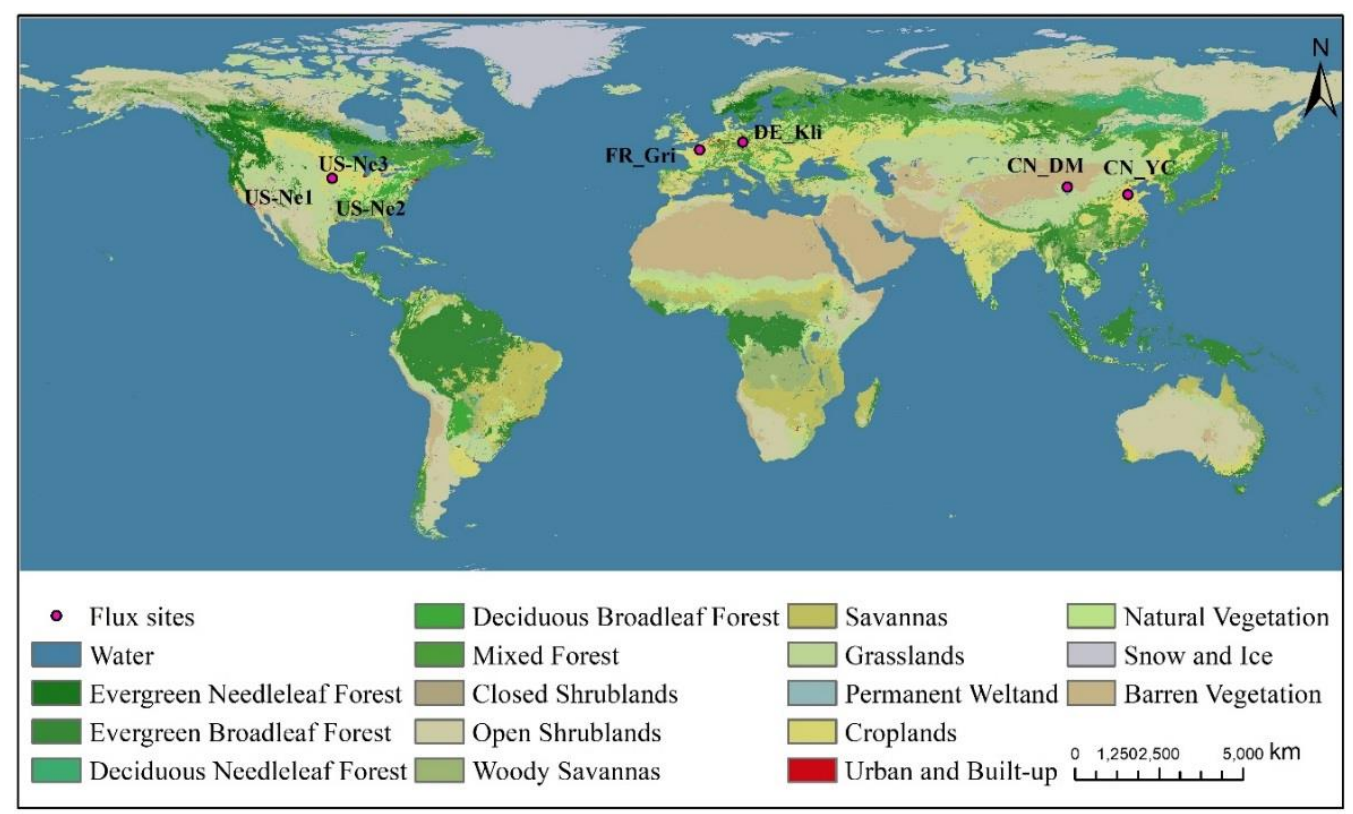

FIGURE 1. Locations of seven maize flux tower sites. The global land cover classification data were produced by the AVHRR (Hansen et al., 2010).

\subsection{MODIS data}

MODIS, the main instrument aboard the Terra Earth Observing System (EOS) satellite for monitoring the seasonality of global terrestrial vegetation, was launched on 18 December 1999. Terra MODIS observes the entire Earth's surface with a period cycle of 1 to 2 days, obtaining data with 36 spectral bands. Beginning in 2000, GPP products were provided by the NASA EOS with a temporal resolution of 8 days at 1$\mathrm{km}$ spatial resolution (Running, 2000).

To evaluate the MOD17-GPP product with eddy covariance flux, the MOD15A2 and MOD17A2 products were obtained from the EOSDIS (http://reverb.echo.nasa.gov). The MOD15A2 data product is the 8-day composites of leaf area index (LAI) and FPAR, and the MOD17A2 is the 8-day composites of GPP and net primary productivity (NPP). The current version of the above two products, the Collection 6 data at a spatial resolution of $500 \mathrm{~m}$, were used in this study.

\subsection{MOD17 algorithm}

The MOD17A2 products are available by summing up the 8-day GPP. The description of the MODIS GPP algorithm was described by Running (2000). The algorithm relies on the light use efficiency $(\varepsilon)$ (Heinsch et al., 2006) linearly relating GPP to the absorbed photosynthetic radiation (APAR) (Monteith, 1972).

$$
\text { GPP }=\text { PAR } \times \text { FPAR } \times \varepsilon
$$

where $P A R$ is the photosynthetically active radiation and FPAR is the fraction of the photosynthetic active radiation absorbed by vegetation. Estimates of 8-day mean daily FPAR with the spatial resolution of $500 \mathrm{~m}$ were provided by the MODIS team (Running, 2015). The parameter of $\varepsilon$ is the LUE for GPP. 
$\boldsymbol{\varepsilon}=\boldsymbol{\varepsilon}_{\max } \times \mathrm{T}_{\text {mircalar }} \times \mathrm{VPD}_{\text {sala }}$

where $\varepsilon_{\max }$ is the maximum LUE from the look-up table (Running, 2000), relying on

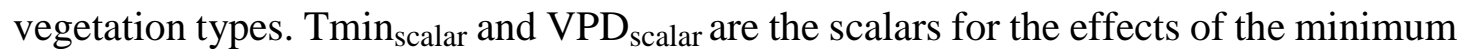
temperature and vapor pressure deficit on LUE of vegetation, respectively. The parameters of $\mathrm{VPD}_{\max }$ and $\mathrm{VPD}_{\min }, \mathrm{Tmin}_{\min }, \mathrm{Tmin}_{\max }$ and $\varepsilon_{\max }$ can be acquired by the biome parameters look-up table (BPLUT) in the user guide of MODIS17.

$$
f\left(T_{\text {min }}\right)=\left\{\begin{array}{lr}
0, & T_{\text {min }}<T_{\text {mimin }} \\
\frac{T_{\text {min }}-T_{\text {mimin }}}{T_{\text {mimax }}-T_{\text {mimin }}}, & T_{\text {mimin }}<T_{\text {min }}<T_{\text {minax }} \\
1, & T_{\text {min }}>T_{\text {mimax }}
\end{array}\right.
$$

Tmin is the minimum daily temperature $\left({ }^{\circ} \mathrm{C}\right)$. Tmin $\min _{\text {in }}$ is the lower limit of the daily minimum air temperature; and $\operatorname{Tmin}_{\max }$ is the upper limit of the daily minimum air temperature.

$$
f(V P D)= \begin{cases}0, \quad(V P D)> & (V P D)_{\text {max }} \\ \frac{(V P D)_{\text {max }}-(V P D)}{(V P D)_{\text {max }}-(V P D)_{\text {min }}}, & (V P D)_{\text {min }}<(V P D)<(V P D)_{\text {max }} \\ 1, \quad(V P D)< & (V P D)_{\text {min }}\end{cases}
$$

$\operatorname{VPD}(\mathrm{Pa})$ is the average vapor pressure deficit. $\mathrm{VPD}_{\min }$ is the lower limit value of daytime mean vapor pressure deficit; and $\mathrm{VPD}_{\max }$ is the upper limit value of daytime mean vapor pressure deficit.

\subsection{FPAR Reconstruction}

The temporal profile of FPAR should be smooth, as the result of the FPAR of the canopy changes slowly throughout the year. However, the FPAR from remote sensing data sometimes changes abruptly due to the noise of bad weather conditions such as clouds, persistent rainy days and fog. To reduce the noise of the contaminated FPAR, a time-series reconstructing algorithm called the Savizky_Golay filter (Chen et al., 2004) was employed in this study as follows:

$$
Y_{i}^{*}=\frac{1}{2 m+1} \sum_{i=-m}^{j=m} C_{j} Y_{i+j}
$$

where $Y$ is the original time-series data; $Y_{i}^{*}$ is the reconstructed time-series data; $C_{j}$ is the jth weight of the filter window; and $2 \mathrm{~m}+1$ is the size of filter window (Ma and Veroustraete, 2006).

\subsection{Calibrating the LUE}

According to the LUE model, the parameter of $\varepsilon$ was calibrated using the following formula: 


$$
\varepsilon=\mathrm{GPP} \times \mathrm{FPAR}^{-1} \times \mathrm{PAR}^{-1}
$$

where GPP is from the eddy covariance measurements. FPAR is from the MOD15 product and $P A R$ is estimated from incident shortwave radiation (SWR) multiplied by 0.45 . The maximum $\varepsilon$ value was defined corresponding to the maximum GPP in the growing seasons in equation (6). In addition, the maximum LUE in each site are shown in Table 2.

TABLE 2. The calibrated LUE of seven maize sites.

\begin{tabular}{lcclllll}
\hline Site & US_Ne1 & US_Ne2 & US_Ne3 & DE_Kli & FR_Gri & CN_DM & CN_YC \\
\hline$\varepsilon_{\max }(\mathrm{g}$ C/MJ $)$ & 3.31 & 2.42 & 3.19 & 2.17 & 2.29 & 2.25 & 2.25 \\
\hline
\end{tabular}

\subsection{Statistical indicator for validation}

Three statistical indicators were used to assess the performance of the model goodness, including determination coefficient $\left(\mathrm{R}^{2}\right)$, root mean square error (RMSE) and the relative error (RE). They were calculated as follows:

$$
\begin{aligned}
& R^{2}=\left(\frac{\sum_{i=1}^{N}(G P P E C(i)-\overline{G P P C})}{\sqrt{\sum_{i=1}^{N}\left(G P P P_{i m}(i)-\overline{G P P E C}\right)^{2}} \sqrt{\sum_{i=1}^{N}(G P P \operatorname{sim}(i)-\overline{G P P s i n})^{2}}}\right)^{2} \\
& R M S E=\sqrt{\frac{1}{N} \sum_{i=1}^{N}\left(G P P_{\sin }(i)-G P P E(i)\right)^{2}} \\
& R E=\frac{G P P_{s i m}-G P P E C}{G P P E C} \times 100 \%
\end{aligned}
$$

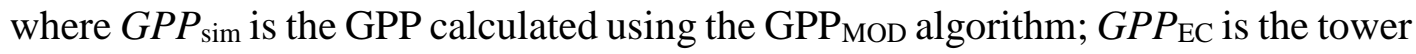
measured GPP; the over-bars represent the mean value; and $\mathrm{N}$ is the sample number.

\section{Results}

\subsection{Validation of MOD17 GPP product}

In the American and European sites, the MODIS GPP could not capture the beginning of the growing season of the maize. Additionally, there was a large underestimation in the MODIS GPP during the growing season in seven maize sites, as well as substantial biases in the non-growing seasons in the American and European sites (Figure 2). In terms of the overall amount of the GPP, the agreements between $\mathrm{GPP}_{\mathrm{EC}}$ and $\mathrm{GPP}_{\mathrm{MOD}}$ changed in different sites with an $\mathrm{R}^{2}$ from 0.45 to 0.93 (Figure 3 ). 

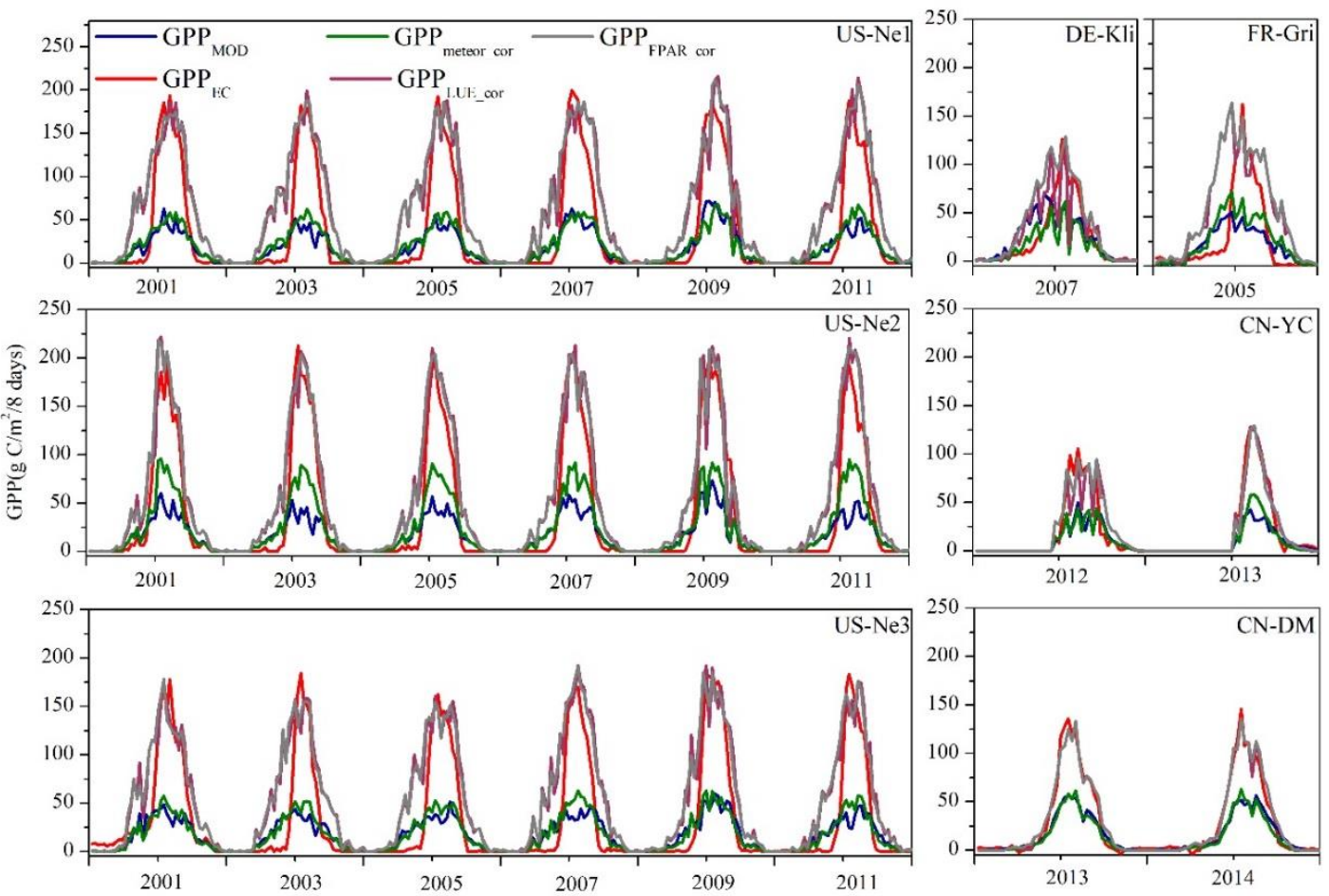

FIGURE 2. The figure of Simulation meteor_cor(GPP meteor_cor $_{2}$, Simulation LUE_cor(GPPLUE_cor $)$, Simulation FPAR_cor(GPP FPAR_cor $\left._{2}\right)$ GPP ${ }_{E C}, G P P_{M O D}$ at the seven sites. GPP meteor_cor was calculated using the MODIS_GPP algorithm which was driven by the observed meteorological data (PAR, VPD and $\mathrm{T}_{\min }$ ), FPAR(MOD15A2), and other default parameters; GPP LUE_cor was calculated by the calibrated $\varepsilon_{0}$ values on the base of GPP meteor_cor; GPPFPAR_cor was calculated with the reconstructed FPAR based on the GPP LUE_cor; $_{\text {GPP }}$ EC was the eddy covariance flux tower observed GPP; and

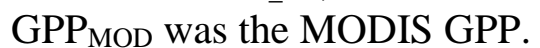

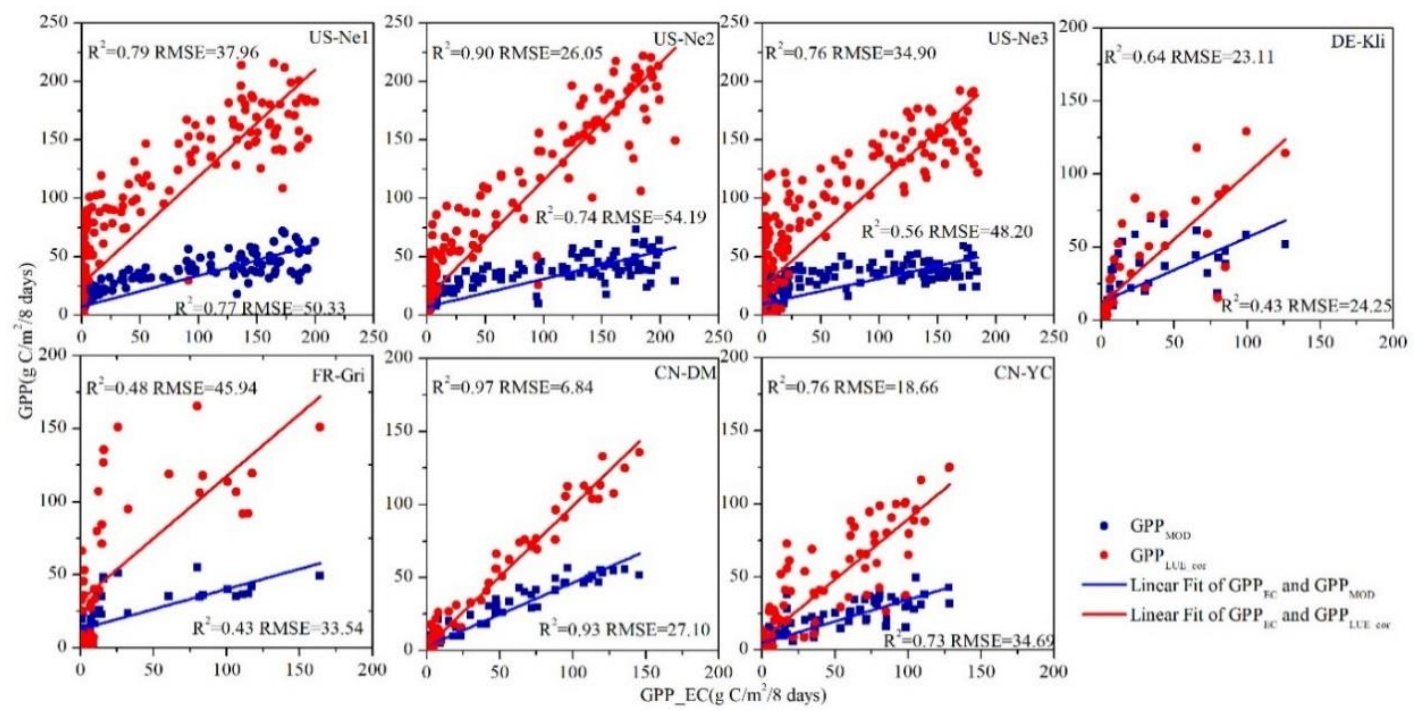

FIGURE 3. The scatter plots between GPPMOD, GPPLUE_cor and GPP $P_{E C}$ at seven maize eddy flux tower sites.

\subsection{Improving MOD17 GPP product}


To understand the errors of the GPPмо algorithm, three simulations were conducted. In the Simulation meteor_cor, only meteorological data such as PAR, VPD, and T were replaced by the observation value from the flux tower and other parameters (FPAR, and $\left.\varepsilon_{\max }\right)$ were default in the MODIS algorithm. In the Simulation LUE_cor, based on the Simulation meteor_cor, LUE was calibrated by the eddy covariance flux tower observation. In the Simulation FPAR_cor, based on the Simulation LUE_cor, the parameter of FPAR from the MOD15 was reconstructed to reduce the noise. The parameter details of the three simulations are shown in Table 3.

TABLE 3. Parameters used for the improving of MODIS GPP algorithm.

\begin{tabular}{lccccccc}
\hline \multicolumn{1}{c}{ GPP } & FPAR & Meteorology data & $\varepsilon_{\max }$ & $\mathrm{T}_{\min \text { max }}$ & $\mathrm{T}_{\min \text { min }}$ & $\mathrm{VPD}_{\max }$ & $\mathrm{VPD}_{\min }$ \\
\hline GPP MOD & MOD15 FPAR & DAO & 1.004 & 12.02 & -8.00 & 43 & 6.5 \\
GPP $_{\text {meteor_cor }}$ & MOD15 FPAR & Surface measure & 1.004 & 12.02 & -8.00 & 43 & 6.5 \\
GPP LUE_cor & MOD15 FPAR & Surface measure & Calibrated & 12.02 & -8.00 & 43 & 6.5 \\
GPP $_{\text {FPAR_cor }}$ & reconstruction & Surface measure & Calibrated & 12.02 & -8.00 & 43 & 6.5 \\
\hline
\end{tabular}

Compared with GPPMOD, simulation meteor_cor was replaced by the local meteorological data in the MODIS GPP algorithm, which only slightly improved the MODIS GPP at seven sites. However, Simulation LUE_cor greatly improved the amount of the MODIS GPP by using the $\varepsilon$ calibrated by the eddy covariance flux tower observation. Meanwhile, the Simulation FPAR_cor could reduce the GPP noise due to the contaminated FPAR in the site of DE-Kli (Figure 4) with GPP improvement from 1501.9 ( $\mathrm{g} \mathrm{C}^{2} \mathrm{~m}^{2} /$ year) to 1798.5 (g C/m²/year) and $\mathrm{R}^{2}$ from 0.64 to 0.78 . After improving the MODIS GPP algorithm step by step, from Simulation meteor_cor and Simulation LUE_cor to Simulation FPAR_cor, the amount of GPP increased markedly (Figure 2 and Table 4) while $\mathrm{R}^{2}$ between the simulation GPP and the observed GPP remains unchanged (Figure 3 and Table 5).

From a statistical point of view, the simulation GPPs are indeed overestimated. However, concerning the pattern of the whole year, the simulated GPPs perfectly fit EC GPPs in the growing season of the maize. In the American and European sites, the FPAR was high in the non-growing seasons, which leads to the high amount of the simulated GPPs (Figure 2 and Figure 5). The deviation of the FPAR in American and European sites may cause the high $\mathrm{R}^{2}$ between the simulated GPP and EC GPP. However, there is no deviation in the CD_YC and CD_DM sites, and the $\mathrm{R}^{2}$ is lower than those in American and European sites. 

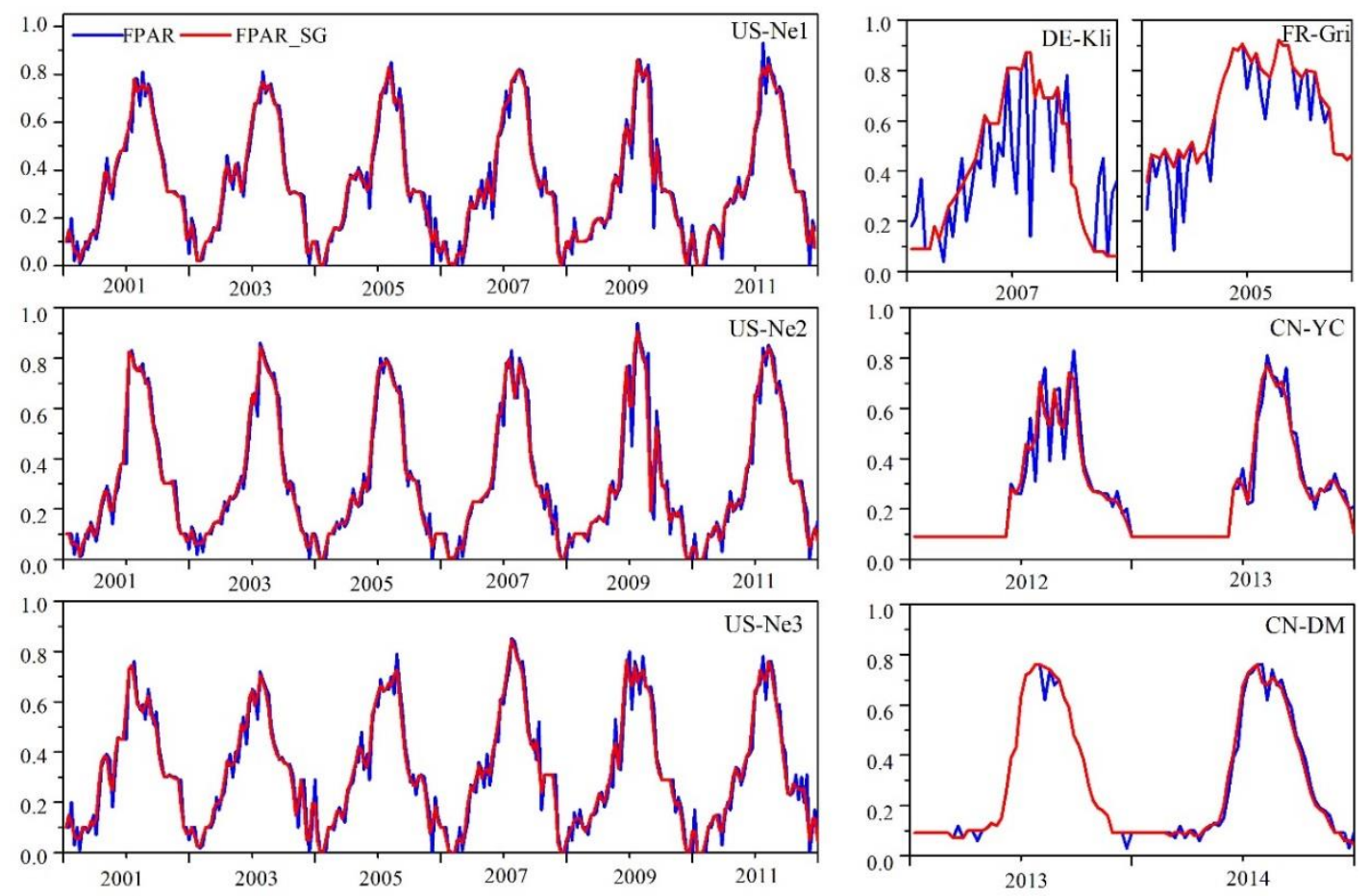

FIGURE 4. FPAR and reconstructed FPAR (FPAR_SG) at seven flux sites.
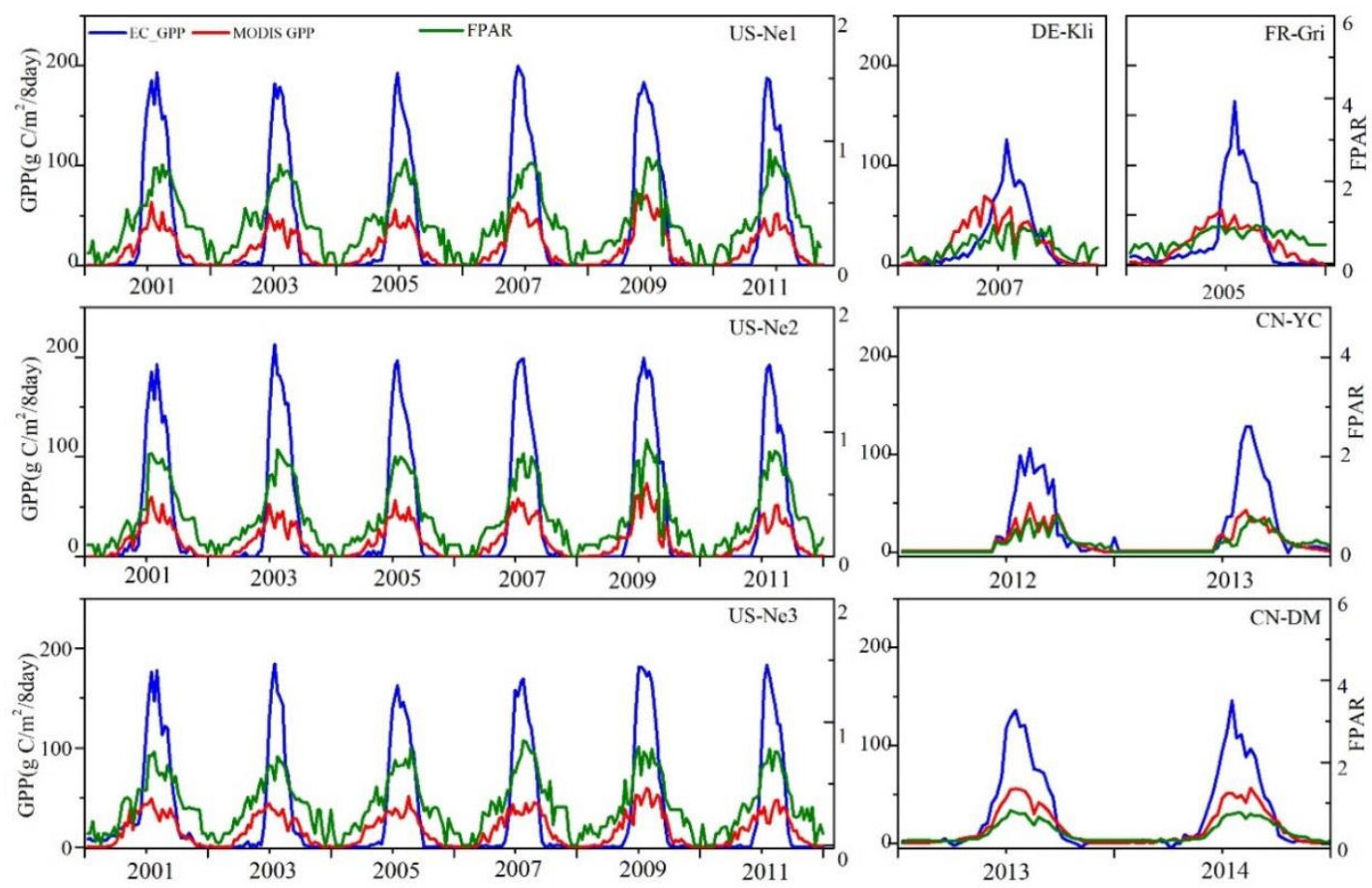

FIGURE 5 The relationship between the GPP $\mathrm{EC}_{\mathrm{EC}} \mathrm{GPP}_{\mathrm{MOD}}$ and FPAR at seven maize eddy flux tower sites. 
TABLE 4. Different GPPs from seven maize eddy covariance flux towers.

\begin{tabular}{|c|c|c|c|c|c|c|c|}
\hline $\mathrm{g} \mathrm{C} / \mathrm{m}^{2} /$ year & US_Ne1 & US_Ne2 & US_Ne3 & DE_Kli & FR_Gri & CN_DM & CN_YC \\
\hline GPP $_{\text {MOD }}$ & 790.9 & 753.4 & 782.6 & 1066.8 & 933.4 & 700.8 & 710.9 \\
\hline $\mathrm{GPP}_{\text {meteor_cor }}$ & 880.4 & 1066.4 & 814.6 & 719.8 & 1170.6 & 628.9 & 754.0 \\
\hline $\mathrm{GPP}_{\text {LUE_cor }}$ & 2793.4 & 2472.0 & 2486.8 & 1501.9 & 2577.6 & 1355.4 & 1689.2 \\
\hline $\mathrm{GPP}_{\mathrm{FPAR} \_ \text {cor }}$ & 2815.5 & 2496.8 & 2496.7 & 1798.5 & 2703 & 1373.0 & 1706.3 \\
\hline $\mathrm{GPP}_{\mathrm{EC}}$ & 1707.3 & 1774.6 & 1550.3 & 1133.2 & 1283.4 & 1296.9 & 1676.3 \\
\hline
\end{tabular}

TABLE 5. Statistical indices of different GPPs at seven maize eddy flux tower sites.

\begin{tabular}{|c|c|c|c|c|c|c|c|c|c|c|c|c|}
\hline \multirow{2}{*}{ Sites } & \multicolumn{3}{|c|}{$\mathrm{GPP}_{\mathrm{MOD}}$} & \multicolumn{3}{|c|}{$\mathrm{GPP}_{\text {meteor_cor }}$} & \multicolumn{3}{|c|}{ GPP LUE_cor } & \multicolumn{3}{|c|}{ GPPPPAR_cor $_{\text {FPA }}$} \\
\hline & $\mathrm{RE}(\%)$ & RMSE & $\mathrm{R}^{2}$ & $\mathrm{RE}(\%)$ & RMSE & $\mathrm{R}^{2}$ & $\operatorname{RE}(\%)$ & RMSE & $\mathrm{R}^{2}$ & $\mathrm{RE}(\%)$ & RMSE & $\mathrm{R}^{2}$ \\
\hline US_Ne1 & -53.7 & 50.3 & 0.77 & -48.4 & 48.3 & 0.79 & 38.9 & 37.9 & 0.79 & 39.4 & 37.3 & 0.81 \\
\hline US_Ne2 & -57.5 & 54.2 & 0.74 & -39.9 & 40.37 & 0.90 & 28.2 & 26.1 & 0.90 & 28.9 & 25.8 & 0.91 \\
\hline US_Ne3 & -49.5 & 48.2 & 0.76 & -47.5 & 43.7 & 0.76 & 37.7 & 34.9 & 0.76 & 37.9 & 34.8 & 0.77 \\
\hline DE_Kli & -5.9 & 24.5 & 0.43 & -36.5 & 23.0 & 0.65 & 24.5 & 23.1 & 0.64 & 36.9 & 24.3 & 0.78 \\
\hline FR_Gri & -27.3 & 33.5 & 0.43 & -8.8 & 30.3 & 0.49 & 50.2 & 45.94 & 0.48 & 52.5 & 46.8 & 0.53 \\
\hline CN_DM & -45.9 & 27.1 & 0.93 & -51.5 & 27.1 & 0.97 & 4.3 & 6.84 & 0.97 & 6.2 & 6.9 & 0.97 \\
\hline CN_YC & -57.6 & 34.7 & 0.73 & -55 & 32.2 & 0.76 & 0.8 & 18.66 & 0.76 & 1.7 & 16 & 0.83 \\
\hline
\end{tabular}

\section{Discussion}

\subsection{Statistical characteristics of carbon fluxes across different regions}

This study analyzed the statistical characteristics of carbon fluxes from maize croplands in different regions around the world, which provides valuable information to evaluate the carbon cycle in maize farmland ecosystems. The largest productivity of maize crops appeared in one of the American sites with GPP of $1774.6 \mathrm{~g} \mathrm{C} / \mathrm{m}^{2} /$ year, which had the largest mean LUE with the value of $2.97 \mathrm{~g} \mathrm{C} / \mathrm{MJ}$. The YC site (a special explanation) had a mean GPP of $1676.3 \mathrm{~g} \mathrm{C} / \mathrm{m}^{2} /$ year with spring wheat $(717.3 \mathrm{~g}$ $\mathrm{C} / \mathrm{m}^{2} /$ year) and summer maize ( $959 \mathrm{~g} \mathrm{C} / \mathrm{m}^{2} /$ year). Deducting the GPP of spring wheat from the CN_YC site, the smallest productivity of these maize crop sites was the CN_YC site, which was in the continental monsoon climate zone. However, the GPP of CN_DM site was slightly higher than that of the DE-Kli site but lower than those of US_Ne1, US-Ne1 and US-Ne3.

\subsection{The Maximum LUE and its uncertainty in the GPP}

The maximum LUE, indicating the potential conversion efficiency of absorbed PAR under the ideal vegetation growing condition, has significance in the LUE model in the GPP simulation (Xiao et al., 2011). The maximum LUE was considered as a universal constant across plant function types in previous models (Potter et al., 1993). In the GPPмор algorithm, the default maximum LUE of crops is $1.044 \mathrm{~g} \mathrm{C} / \mathrm{MJ}$ (Running, 2015), which contains all types of crops without consideration of $C 3$ and C4. Maize is a $\mathrm{C} 4$ plant, and its maximum LUE was $2.66 \mathrm{~g} \mathrm{C/MJ}$, in the middle stream of the Heihe River basin (Wang et al., 2013). The maximum LUE of maize was determined as 
$2.84 \pm 0.57 \mathrm{~g} \mathrm{C} / \mathrm{MJ}$ by the flux tower data (Chen et al., 2015). In this study, the mean maximum LUE of these seven sites was $2.55 \mathrm{~g}$ C/MJ, calculated by the GPP $\mathrm{EC}_{\mathrm{E}}$ (measured by eddy covariance method), FPAR(MOD15A2) and PAR (meteorological measurements).

In these seven maize sites, the uncertainties of the underestimates were present in the LUE because the tower observing meteorological data only gently improve the GPРмор algorithm. However, after using the LUE calibrated by the eddy covariance flux tower data, the magnitude of GPРмов can be dramatically improved. Many previous works on the validation of GPРмод proved that the LUE was the primary reason for GPP underestimate (Turner et al., 2003; Turner et al., 2006; Fu et al., 2012).

\subsection{The FPAR and its uncertainty on the GPP}

\subsubsection{The uncertainty of contaminated FPAR}

It is apparent that the accuracy of the MODIS GPP product is highly reliant on the MODIS FPAR product and that the retrieval of FPAR under bad conditions with persistent cloud cover, fog, rainy weather, and low solar angles was extremely difficult (Coops et al., 2007). As a result, extraction of a high FPAR data for each of the 8-day time intervals can be problematic, leading to the uncertainty of the MODIS GPP. To obtain FPAR with no noise from seven maize sites under conditions with low solar angles and persistent cloud cover is exceptionally challenging.

In this study, the noise of FPAR primarily appears at the DE-Kli and FR-Gri sites, which were in the ocean climate with a lot of cloudy and rainy weather (Figure 4). According to our calculation results, the GPP in the ocean climate at DE-Kli site was most affected by the noise of FPAR at $14 \%$, followed by the FR-Gri site at $7 \%$. After using the reconstructed FPAR as the input in Simulation FPAR_cor, the $\mathrm{R}^{2}$ between the

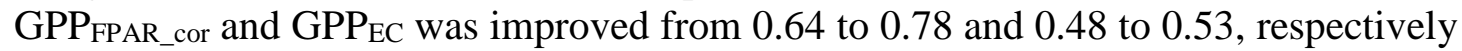
(Table 5). Meanwhile, the monsoon climate can experience significant rainfall in the summer in the growing season, such as the $\mathrm{CN}-\mathrm{YC}$ site. At CN-YC site, the $\mathrm{R}^{2}$ between

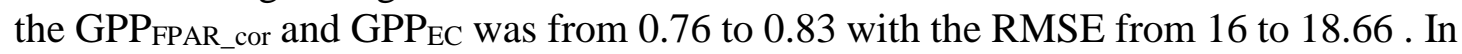
the continental climate of the American sites and CN-DM site, the GPP was slightly influenced by the contaminated FPAR.

In the absence of field measurements of FPAR, this study inferred the parameter of FPAR assimilated from the MODIS product relying on peer-reviewed literatures. The prevalence of persistent cloud covers coupled with fog at high relative daily humidity in the growing season resulted in large uncertainty in the MODIS FPAR (Gebremichael and Barros, 2006). This study considered that the current MODIS algorithm, relying on DAO data for meteorological input, worked well in sunny days but raised challenges in complex weather, such as rainy and foggy days. Because regional weather was influenced by climate change, the spatial patterns of cloud cover filled with fog and rainfalls cannot be captured by the MODIS FPAR, which causes uncertainty and oscillation of the GPP in the growing season.

\subsubsection{The uncertainty of canopy heterogeneity}


Spatial heterogeneities of natural vegetation and land-surface affect the surface exchange of energy, water, and carbon, and the lower atmospheric circulation over a wide range of scales (Falge et al., 2002). The orientation and size of footprints vary remarkably according to the wind speed and direction from season to season (Chen et al., 2009). There is also the problem of the mismatch of the representativeness between the flux tower and the satellite observation of the GPP ${ }_{\text {MOD }}$ product. This study took no account of the footprint of observation in the eddy covariance flux tower because the original footprint was not big enough to be a pixel in the MODIS GPP products. Similarly to most studies, there are some areas to be improved in future studies, such as the footprint of eddy covariance flux.

With the comparison of the GPP EC $_{\text {and GPP }}$ MOD, simulated GPP have a systematic basis in the non-growing season in the American and European sites. In other words, GPPMOD and simulated GPP cannot capture the start of the growing season but go into the growing season ahead of time. The basis of GPPMOD and simulated GPP at the American and European sites correspond well with the FPAR from the MOD15A2H, which is an important parameter reflecting the condition of vegetation growth in the MODIS GPP algorithm. There are obvious reasons that the FPAR of the American and European sites mix maize with other vegetation. At the DE-Kli site, the landscapes cultivate evergreen forests coupled with a diversity of both annual crops, causing the FPAR to mix with forest. Meanwhile, the cropping systems, such as an alternative cropping system, make a diversity of the crops scatter near European and American sites, and the FPAR of some crops that start growing earlier than the maize was caught by the MOD15A2H. Therefore, canopy heterogeneity and a diversity of crops (due to the alternative cropping) caused a high value of FPAR in the non-growing season of maize, which brought biases to the FPAR and uncertainty to the MODIS GPP.

However, in the Asian sites, single corn crop was planted in wide areas in CN-DM and CN-YC sites. Therefore, the canopy heterogeneity was relatively small to ensure the FPAR without the interference of other crops, which made the MODIS GPP and Simulation GPP correctly capture the seasonal dynamics of maize growing in Asian sites.

\subsection{The uncertainty of eddy covariance}

The uncertainty of eddy covariance also exists, notably in the estimation of ecosystem respiration (Goulden et al., 1996) and interpolation errors caused by missing data. GPP is calculated as the net ecosystem exchange (NEE) plus ecosystem respiration (ER). As a result, various flux NEE partition methods will lead to different GPP amounts, even at the same site (Reichstein et al., 2005; Desai et al., 2008). In this study, daytime respiration employs the Van't Hoff function (nighttime-based method: GPP_NB). With this method, the result can be affected by the suppression of the turbulence and dominance of advective fluxes at night (Lasslop et al., 2010).

\section{Conclusions}

In this study, the MODIS GPP product of the maize is validated by the eddy covariance tower flux data at seven sites in America, Europe and Asia. The MODIS 
GPP was underestimated by approximately $6 \%$ to $58 \%$. The reasons for underestimation are as follows:

The marked influence of the accuracy of MODIS GPP was the LUE in each site. In the MODIS algorithm, the problem of the underestimate in LUE is a common phenomenon on the global scale. In the MODIS GPP algorithm, the maximum LUE of crops is defaulted at $1.044 \mathrm{~g} \mathrm{C} / \mathrm{MJ}$, which contains all the types of crop without differentiation of $\mathrm{C} 3$ and $\mathrm{C} 4$. In fact, the mean calibration maximum LUE of these seven sites was $2.55 \mathrm{~g} \mathrm{C} / \mathrm{MJ}$. The disparities between the default LUE in the MODIS GPP algorithm and the calibrated LUE from eddy flux tower are the primary reason for the underestimation of MODIS GPP.

In addition, the contaminated FPAR is a big contributor to the underestimate of MODIS GPP.

Meanwhile, in America and Europe, canopy heterogeneity and the diversity of crops caused by alternative cropping led to the deviation of catching the growing season of the maize crop, which introduces errors to the FPAR and uncertainty to the MODIS GPP.

When the MODIS GPP is applied to a specific area, users should consider the regional weather, the canopy heterogeneity and calibrate LUE from the eddy flux tower to minimize the noise of the FPAR and LUE for better accuracy of the MODIS GPP product. After improving the parameter of LUE and FPAR, the MODIS GPP product is applicable for global GPP calculations in temporal and spatial scales.

\section{Acknowledgements}

This work is jointly supported by the National Natural Science Foundation of China (41641058), National Key Technology R\&D Program of China (2016YFC0500106), Special Project of Science and Technology Basic Work (2014FY210800-5), and the Fundamental Research Funds for the Central Universities in China (SWU116088). We are grateful to the availability of the tower flux data of maize sites from Fluxnet and ChinaFlux.

\section{References}

Chen B Z, Black T A, Coops N C, Hilker T, Trofymow J A, Morgenstern K (2009) Assessing tower flux footprint climatology and scaling between remotely sensed and eddy covariance measurements. Boundary-Layer Meteorol, 130(2): 137-167

Chen J, Jönsson P, Tamura M, Gu Z, Matsushita B, Eklundh L (2004) A simple method for reconstructing a high-quality NDVI time-series data set based on the SavitzkyGolay filter. Remote Sens Environ, 91 (3-4): 332-344

Chen T, van der Werf G R, Gobron N, Moors E J, Dolman A J (2014) Global cropland monthly gross primary production in the year 2000. Biogeosciences, 11(14): 23652366

Cohen W B, Maiersperger T K, Yang Z Q, Gower S T, Turner D P, Ritts W D, Berterretche M, Running S W (2003) Comparisons of land cover and LAI estimates 
derived from ETM plus and MODIS for four sites in North America: a quality assessment of 2000/2001 provisional MODIS products. Remote Sens Environ, 88(3): 233-255

Coops N C, Black T A, Jassal R S, Trofymow J A, Morgenstern K (2007) Comparison of MODIS, eddy covariance determined and physiologically modelled gross primary production (GPP) in a Douglas-fir forest stand. Remote Sens Environ, 107(3): 385-401 Falge E, Baldocchi D, Tenhunen J, Aubinet M, Bakwin P, Berbigier P, Bernhofer C, Burba G, Clement R, Davis K J, Elbers J A, Goldstein A H, Grelle A, Granier A, Guðmundsson J, Hollinger D, Kowalski A S, Katul G, Law B E, Malhi Y, Meyers T, Monson R K, Munger JW, Oechel W, Paw U K T, Pilegaard K, Rannik Ü, Rebmann C, Suyker A, Valentini R, Wilson K, Wofsy S (2002) Seasonality of ecosystem respiration and gross primary production as derived from FLUXNET measurements. Agric Meteorol, 113(1-4): 53-74

Fensholt R, Sandholt I, Rasmussen M S (2004) Evaluation of MODIS LAI, fAPAR and the relation between fAPAR and NDVI in a semiarid environment using in situ measurements. Remote Sens Environ, 91(3-4): 490-507

Fu G, Shen Z, Zhang X, Shi P, He Y, ZhangY, Sun W, Wu J, Zhou Y, Pan X (2012) Calibration of MODIS-based gross primary production over an alpine meadow on the Tibetan Plateau. Can J Rem Sens, 38(2): 157-168

Gebremichael M, Barros A P (2006) Evaluation of MODIS gross primary productivity (GPP) in tropical monsoon regions. Remote Sens Environ, 100(2): 150-166

Gilmanov T G, Aires L, Barcza Z, Baron V S, Belelli L, Beringer J, Billesbach D, Bonal D, Bradford J, Ceschia E, Cook D, Corradi C, Frank A, Gianelle D, Gimeno C, Gruenwald T, Guo H, Hanan N, Haszpra L, Heilman J, Jacobs A, Jones M B, Johnson D A, Kiely G, Li S, Magliulo V, Moors E, Nagy Z, Nasyrov M, Owensby C, Pinter K, Pio C, Reichstein M, Sanz M J, Scott R, Soussana J F, Stoy P C, Svejcar T, Tuba Z, Zhou G (2010) Productivity, respiration, and light-response parameters of world grassland and agroecosystems derived from flux-tower measurements. Rangeland Ecol Manag, 63 (1): 16-39

Gitelson A A, Vina A, Masek J G, Verma S B, Suyker A E (2008) Synoptic monitoring of gross primary productivity of maize using Landsat data. IEEE Geosci Remote Sens Lett, 5(2): 133-137

Goulden M L, Munger J W, Fan S, Daube B C, Wofsy S C (1996) Measurements of carbon sequestration by long-term eddy covariance: methods and a critical evaluation of accuracy. Glob Change Biol, 2(3): 169-182

Hansen M C, Defries R S, Townshend J R G, Sohlberg R (2000) Global land cover classification at $1 \mathrm{~km}$ spatial resolution using a classification tree approach. Int $\mathbf{J}$ Remote Sens, 21(6-7): 1331-1364

Heinsch F A, Zhao M, Running SW, Kimball J S, Nemani R R, Davis K J, Bolstad P V, Cook B D, Desai A R, Ricciuto D M, Law B E, Oechel W C, Kwon H, Luo H, Wofsy S C, Dunn A L, Munge J W, Baldocchi D D, Xu L, Hollinger D Y, Richardson A D, Stoy P C, Siqueira M B S, Monson R K, Burns S P, Flanagan L B (2006) Evaluation of 
remote sensing based terrestrial productivity from MODIS using regional tower eddy flux network observations. IEEE Trans Geosci Remote Sens, 44(7): 1908-1925

Jung M, Reichstein M, Margolis H A, Cescatti A, Richardson A D, Arain M A, Arneth A, Bernhofer C, Bonal D, Chen J, Gianelle D, Gobron N, Kiely G, Kutsch W, Lasslop G, Law B E, Lindroth A, Merbold L, Montagnani L, Moors E J, Papale D, Sottocornola M, Vaccari F, Williams C (2015) Global patterns of land-atmosphere fluxes of carbon dioxide, latent heat, and sensible heat derived from eddy covariance, satellite, and meteorological observations. J Geophys Res, 116(G3): 245-255

Lai L, Huang X, Yang H, Chuai X, Zhang M, Zhong T, Chen Z, Chen Y, Wang X, Thompson J R (2016) Carbon emissions from land-use change and management in China between 1990 and 2010. Sci Adv, 2(11): e1611063

Lasslop G, Reichstein M, Papale D, Richardson A D, Arneth A, Barr A, Stoy P, Wohlfahrt G (2010) Separation of net ecosystem exchange into assimilation and respiration using a light response curve approach: critical issues and global evaluation. Glob Change Biol, 16(1): 187-208

Lehuger S, Gabrielle B, Cellier P, Loubet B, Roche R, Béziat P, Ceschia E, Wattenbach M (2010). Predicting the net carbon exchanges of crop rotations in Europe with an agroecosystem model. Agric Ecosyst Environ, 139(3): 384-395

Ma M, Veroustraete F (2006) Reconstructing pathfinder AVHRR land NDVI timeseries data for the Northwest of China. Advances in Space Research, 37(4): 835-840

Monteith J L (1972) Solar-radiation and productivity in tropical ecosystems. J Appl Ecol, 9(3): 747-766

Peng Y, Gitelson A A (2011) Application of chlorophyll-related vegetation indices for remote estimation of maize productivity. Agric Meteorol, 151(9): 1267-1276

Potter C S, Randerson J T, Field C B, Matson P A, Vitousek P M, Mooney H A, Klooster S A (1993) Terrestrial ecosystem production- A process model-based on global satellite and surface data. Global Biogeochem Cycles, 7(4): 811-841

Reichstein M, Falge E, Baldocchi D, Papale D, Aubinet M, Berbigier P, Bernhofer C, Buchmann N, Gilmanov T, Granier A, Grünwald T, Havránková K, Ilvesniemi H, Janous D, Knohl A, Laurila T, Lohila A, Loustau D, Matteucci G, Meyers T, Miglietta F, Ourcival J M, Pumpanen J, Rambal S, Rotenberg E, Sanz M, Tenhunen J, Seufert G, Vaccari F, Vesala T, Yakir D, Valentini R (2005) On the separation of net ecosystem exchange into assimilation and ecosystem respiration: review and improved algorithm. Glob Change Biol, 11(9): 1424-1439

Running S W, Baldocchi D D, Turner D P, Gower S T, Bakwin P S, Hibbard K A (1999) A global terrestrial monitoring network integrating tower fluxes, flask sampling, ecosystem modeling and EOS satellite data. Remote Sens Environ, 70(1): 108-127

Running S W, Nemani R R, Heinsch F A, Zhao M S, Reeves M, Hashimoto H (2004) A continuous satellite-derived measure of global terrestrial primary production. Bioscience, 54(6): 547-560

Sun X, Zhu Z, Wen X, Yuan G, Yu G (2006) The impact of averaging period on eddy fluxes observed at ChinaFLUX sites. Agric Meteorol, 137(3-4): 188-193 
Tang X, Li H, Huang N, Li X, Xu X, Ding Z, Xie J (2015) A comprehensive assessment of MODIS-derived GPP for forest ecosystems using the site-level FLUXNET database. Environ Earth Sci, 74(7): 5907-5918

Tang X, Ma M, Ding Z, Xu X, Yao L, Huang X, Gu Q, Song L (2017) Remotely monitoring ecosystem water use efficiency of grassland and cropland in China's arid and semi-arid regions with MODIS data. Remote Sens, 9(6): 616

Turner D P, Ritts W D, Cohen W B, Gower S T, Running S W, Zhao M, Costa M H, Kirschbaum A A, Ham J M, Saleska S R, Ahl D E (2006) Evaluation of MODIS NPP and GPP products across multiple biomes. Remote Sens Environ, 102(3-4): 282-292 Turner D P, Ritts W D, Cohen W B, Gower S T, Zhao M, Running S W, Wofsy S C, Urbanski S, Dunn A L, Munger J W (2003) Scaling Gross Primary Production (GPP) over boreal and deciduous forest landscapes in support of MODIS GPP product validatio. Remote Sens Environ, 88(3): 256-270

Verma S B, Dobermann A, Cassman K G, Walters D T, Knops J M, Arkebauer T J, Suyker A E, Burba G G, Amos B, Yang H, Ginting D, Hubbard K G, Gitelson A A, Walter-Shea E A (2005) Annual carbon dioxide exchange in irrigated and rainfed maize-based agroecosystems. Agric Meteorol, 131(1-2): 77-96

Wang X, Ma M, Li X, Song Y, Tan J, Huang G, Zhang Z, Zhao T, Feng J, Ma Z,WeiW, Bai Y (2013) Validation of MODIS-GPP product at 10 flux sites in northern China. Int J Remote Sens, 34(2): 587-599

Xiao J, Davis K J, Urban N M, Keller K, Saliendra N Z (2011) Upscaling carbon fluxes from towers to the regional scale: influence of parameter variability and land cover representation on regional flux estimates. J Geophys Res Biogeosci, 116(G3): 115-132 Zhang M, Huang X, Chuai X, Yang H, Lai L, Tan J (2015) Impact of land use type conversion on carbon storage in terrestrial ecosystems of China: a spatial-temporal perspective. Sci Rep, 5(1): 10233

Zhang Y, Yu Q, Jiang J, Tang Y (2008) Calibration of Terra/MODIS gross primary production over an irrigated cropland on the North China Plain and an alpine meadow on the Tibetan Plateau. Glob Change Biol, 14(4): 757-767 